\title{
Safety of users in road evacuation: planning internal processes and guidelines
}

\author{
F. Russo \& C. Rindone \\ Department of Computer Science, Mathematics, \\ Electronics and Transportation, \\ Mediterranea University of Reggio Calabria, Italy
}

\begin{abstract}
In this paper a structured process to plan an urban system in emergency conditions is presented. The internal planning process is described with reference to planning dimensions and to a generic product-plan component. Guidelines for evacuation planning resulting from the SICURO project are presented, with a view to developing and testing an evacuation plan for an urban system in emergency conditions. Quantitative evaluations play an essential role in the guidelines.
\end{abstract}

Keywords: planning process, evacuation, guidelines, system of models.

\section{Introduction}

A generic transportation plan is a product of a planning process. This process is characterized by different planning dimensions and interactions among subjects involved $[2,6,7]$. A specific component of a generic plan is represented by guidelines in which indications for other plans are illustrated.

In some countries, the planning process in emergency conditions is regulated by specific rules. For example, in Italy emergency planning is regulated by Law 24 February 1992, 225 [4]. This type of law can be considered as a guideline for a high level/national plan. To plan a system in emergency conditions it is necessary to assess risk and its relative components: probability, vulnerability and exposure [1,9]. By assessing risk components it is possible to define different types of interventions to prevent effects arising from a generic disastrous event. In this paper we analyse activities forming part of evacuation planning to reduce exposure. In evacuation planning, interventions can be defined and implemented before and/or after a disastrous event. 
In the literature guidelines may be found for evacuation planning relative to different systems (single building, land system, transportation system, industrial system) and a large number of applications have been developed. However, to our knowledge, preventive assessment by means of methods and models relative to quantification of evacuation times has not been carried out.

In this paper we present a proposal of guidelines for the evacuation planning process. We analyse the transportation planning process in emergency conditions. Preventive evaluations of effects produced by the planned intervention are essential elements of the process.

In section 2 the generic transportation planning process is presented. We will refer to the internal process relative to drafting and adopting a plan. In section 3 , transportation planning for a system in emergency conditions is analysed. In section 4 , a proposal for guidelines is illustrated. In section 5 , guideline contents are validated by verification with a local emergency plan.

\section{Transportation planning process}

Transportation planning is a set of processes that generates different products.

The planning process is represented by:

- dimensions by means of which the generic product-plan is defined;

- the pattern of interactions among subjects involved in different planning dimensions by which a product-plan is defined; we may identify a dynamic for the adoption of single plan (internal dynamic process) and a dynamic for progress among different plans (external dynamic process).

In the following we will refer to internal dynamic process.

\subsection{Planning dimensions}

Transportation planning dimensions $[2,7]$ include:

- the area dimension, a function of the area affected by the plan, that is generally classified as: national, relative to a transportation system of a country; regional, relative to a transportation system of a region or part thereof; or local, relative to a transportation system of a town or aggregation of more than one town;

- the time dimension, a function of time for implementing the plan, that is generally classified as: long-term or strategic, referring to interventions that modify the structure of the transportation system and that require long times and considerable financial resources; medium-term or tactical, referring to managerial interventions relative to optimal resource allocation; short-term or operative, referring to interventions to be made in a brief time scale.

- study-in-depth dimension, a function of detail in planning decisions, which is generally classified as: a directional plan which indicates objectives and strategies; a practicable plan that includes a broadening of guidelines recommended in the directional plan and specifications for single transportation subsystems (railway, roads, ...); a feasible plan where, for single interventions formulated within the practicable plan, technical and economic feasibility is analysed. 


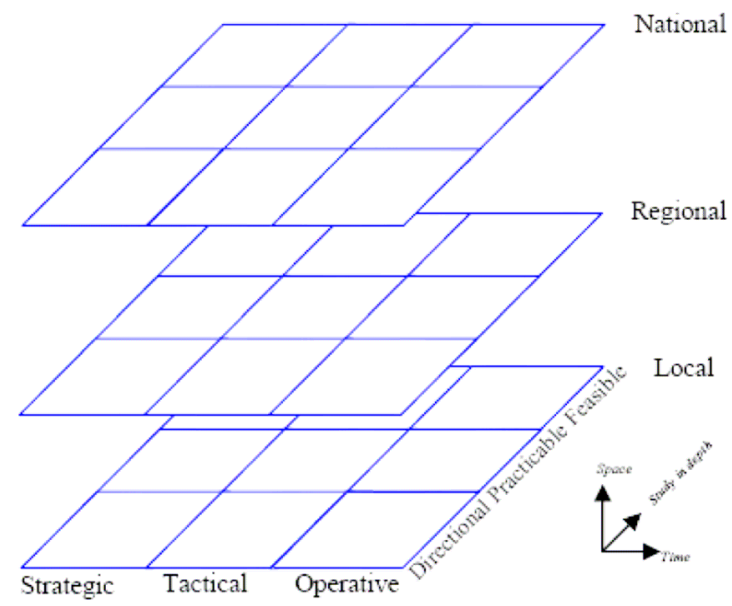

Figure 1: Transportation planning dimensions.

A geometric representation of transportation planning dimensions is presented in Figure 1.

\subsection{Transportation planning process}

The planning process depends on interactions among subjects involved in adopting the plan. Subjects involved in the planning process can be grouped as follows:

- political authorities (P) that define objectives, constraints and general strategies and approve documents during the planning process;

- technical groups (T) that draw up the plan proposal in terms of alternative scenarios;

- other public sectors (A) that contribute to drafting the plan in terms of proposals (e.g. trade union, industrial union, public companies).

The planning process is affected by objectives to pursue with implementation of strategies respecting constraints. Objectives and constraints result from interaction among political and other public groups (relationship 1 - step 1 in Figure 2). Based on objectives and constraints, technical groups develop analysis (relationships 2 and 3 - step 2 in Figure 2): starting from analysis of the present situation, they identify a set of strategies to adopt for pursuing objectives, respecting constraints.

Adoption of different strategies generates alternative scenarios. Effects of scenarios can be simulated and evaluated by means of systems of models. Technicians represent plan effects by means of indicators that can be compared with objectives and constraints before implementation of planned interventions (ex ante evaluations). Results from technical groups support the following phase to choose the best scenario from political bodies. These results partly constitute objectives of interactions among authorities and other public groups (relationships 4 and 5 - in Figure 2). 


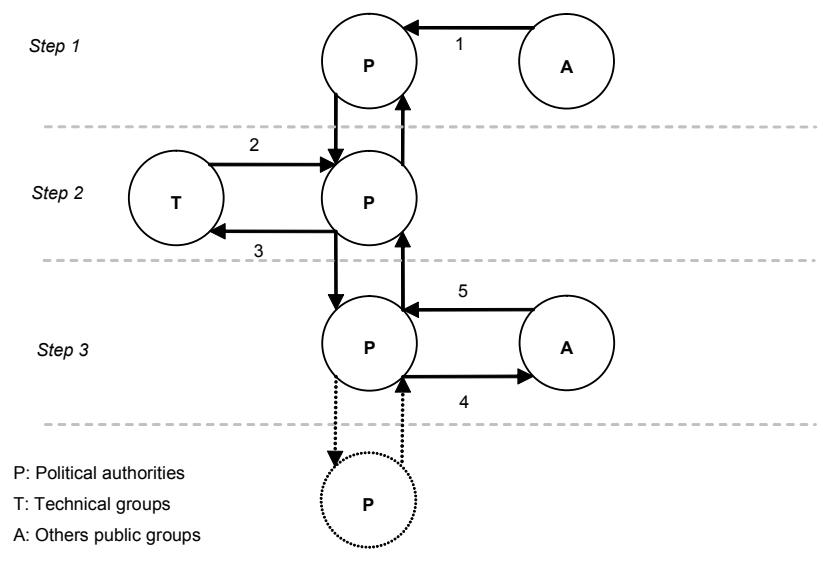

Figure 2: Interactions among involved subjects in planning internal process.

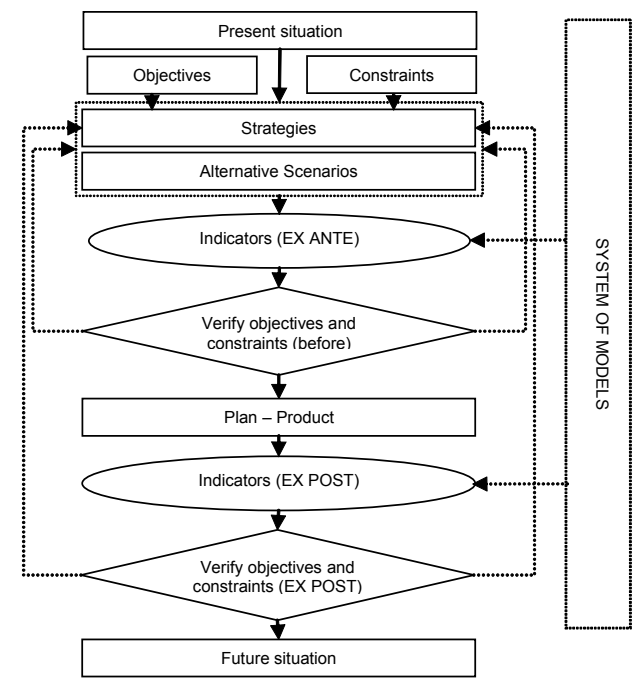

Figure 3: The transportation planning process.

At the end of these interactions the plan-product is adopted. If the plan is implemented a future situation is generated.

During and after the plan's implementation, interventions have to be monitored to verify, by means of a set of indicators (ex post evaluations), whether objectives have been achieved and constraints respected. Monitoring also allows proposals to be modified and scenarios implemented.

The overall diagram of elements and relative relationships of the planning process is reported in Figure 3. 


\subsection{Guidelines for transportation planning}

Guidelines constitute an element of a plan or they can be produced by a normative document (Law, Ordinance, Regulations, ...). Guidelines support the planning process with political or technical indications for plans to implement other planning levels.

In general, guidelines exist for every document relating to a specific state of a planning process. Planning dimensions can be associated to each existing guideline (Figure 4). Contents of guidelines include information on objectives, constraints, strategies and methodology, as an aid to drafting the plan. Methodologies include models and procedures to simulate, evaluate and then structure an alternative plan.

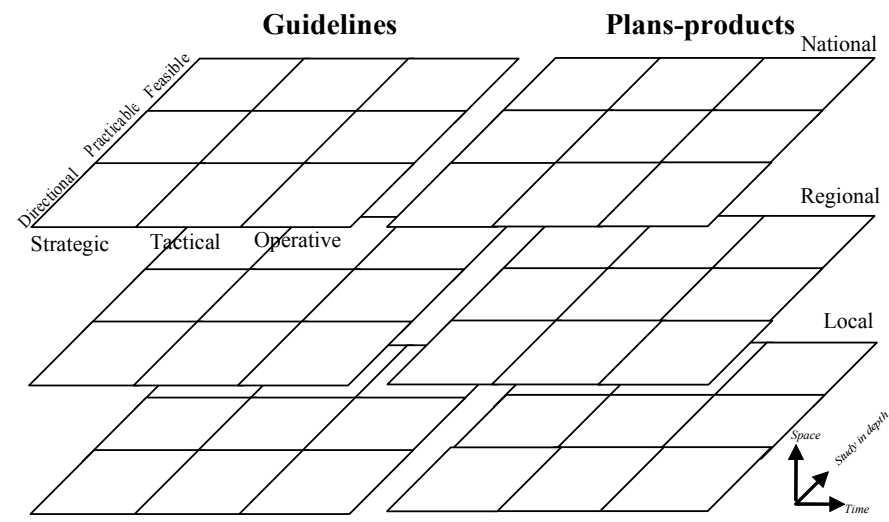

Figure 4: $\quad$ Plan-product and guideline dimensions.

\section{Transportation planning in emergency conditions}

\subsection{Emergency planning process}

The emergency planning process generally follows these phases:

- $\quad$ political authority $(\mathrm{P})$, based on constraints and characteristics of a present situation, identifies objectives and constraints to adopt the local emegency plan;

- $\quad$ political authority (P) assigns to external technical groups (T1) drafting of a plan;

- $\quad$ technical group (T1) presents to Public Authority (P) a planned proposal;

- $\quad$ political authority (P) submits to other public groups (e.g. the population) (A) the planned proposal for possible comments;

- $\quad$ political authority $(\mathrm{P})$, based on remarks of other public groups (A) and political discussions, approves the plan. 
In general, compared to the general transportation planning process (Figure 3 and 4), in an emergency planning process, evaluation using quantitative methods is not envisaged. Hence it is impossible to evaluate how strategies pursue objectives and respect constraints (Figure 5).

\subsection{Interventions for evacuation planning}

Interventions for evacuation planning depend on events that generate emergencies. For each event, there is a specific responsibility to manage within the emergency.

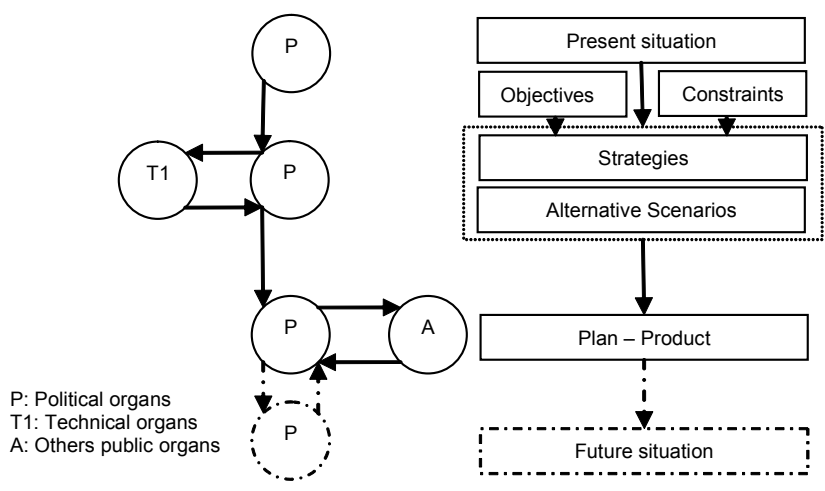

Figure 5: General emergency planning process.

Interventions before a disastrous event can be defined and implemented; these are interventions that mainly modify the transport supply (preventive interventions). There are specific events, for example tsunamis, for which the time interval $\left(t_{3}-t_{1}\right)$, between the instant in which the time when the dangerous event will happen is known or supposed $\left(t_{1}\right)$ and the instant in which the event starts its effects $\left(t_{3}\right)$, is different from zero. For these events it is possible to implement interventions in this defined interval. In most cases such interventions concern demand management (ongoing interventions) (Figure 6).

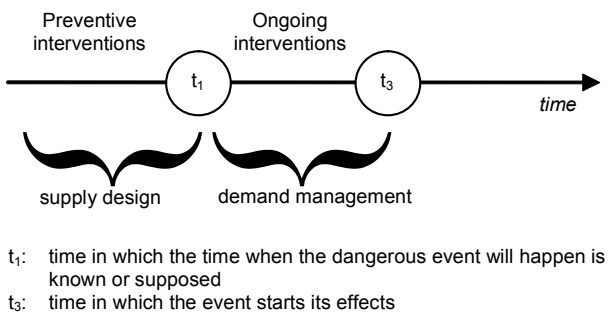

Figure 6: Interventions in an evacuation plan. 


\section{Guidelines for evacuation planning}

An example of guidelines for evacuation planning results from the SICURO project. The project results include: guidelines for evacuation planning after a calamitous event; models and procedures to simulate evacuation to verify local emergency plans.

\subsection{Planning dimensions}

It may be assumed that the project resulting from a regional practicable strategic plan (Output). Guidelines provide indications and tools to design and to verify emergency local plan (Input). Guidelines can then be classified by planning dimensions reported in Table 1.

Planning dimensions of guidelines resulting from the SICURO project are represented in Figure 7.

Table 1: $\quad$ SICURO guideline planning dimensions.

\begin{tabular}{lll}
\hline Planning dimension & Output & Input \\
\hline Territorial & Regional & Local \\
Temporal & Strategic & Operative \\
Study in depth & Directional & Practicable \\
\hline
\end{tabular}

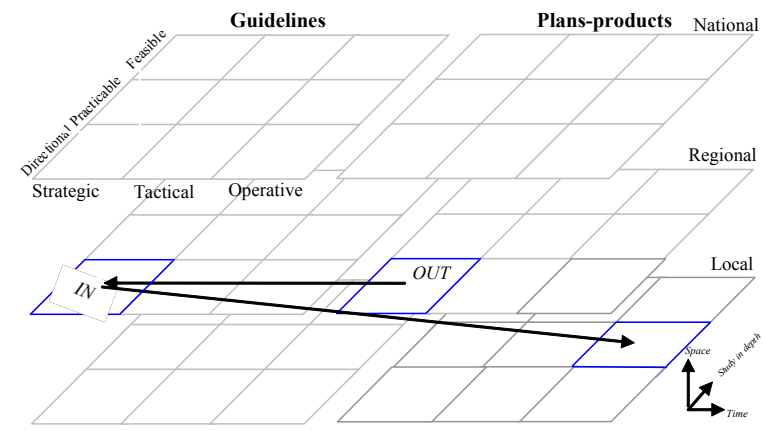

Figure 7: Planning dimensions of guidelines resulting from SICURO project.

\subsection{System of models in the emergency planning process}

By adopting the guidelines resulting from the project it is possible to develop preventive evaluation and test planning evacuation interventions. By means of methods and models resulting from the SICURO project, evacuation times of an urban area may be quantified.

This is facilitated by:

- demand models, to estimate trip generation, modal split with distribution [5]; 
- simulation models of pedestrian outflow in a building, to estimate evacuation times of principal edifices [3];

- simulation models of transport supply-demand interaction for users, to estimate vehicle evacuation times to reach refuge areas [11];

- design of path choice models for emergency vehicles, to estimate times to evacuate weak users and pupils [12];

- $\quad$ simulation models of the refuge area for users, to estimate access times [13]. All resulting methods and models are implemented in a system of models that allows to a technical organ (T2), within an emergency planning process, to verify whether strategies pursuing objectives respect constraints. Thus feedback can be generated within the evacuation planning process (Figure 8).

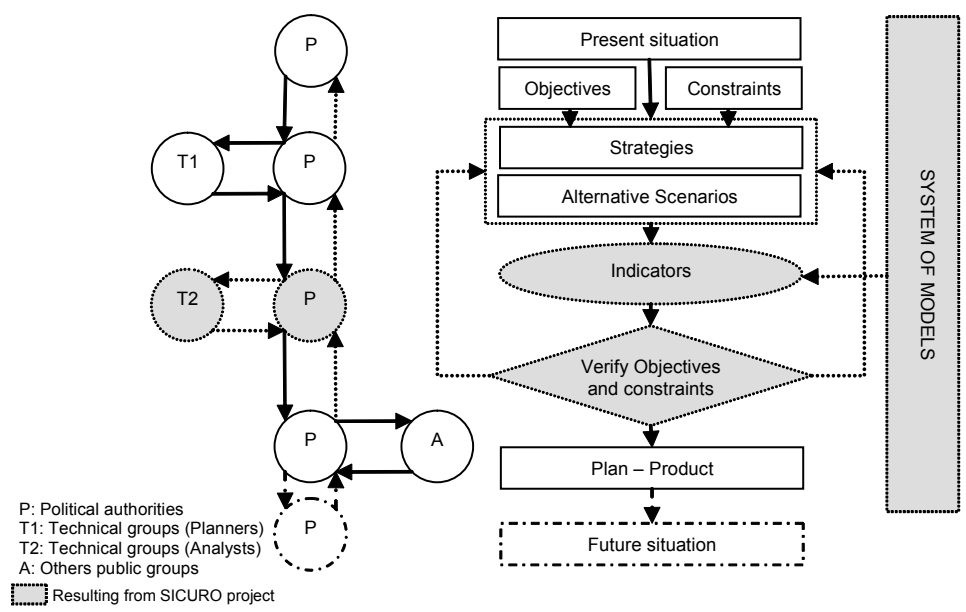

Figure 8: $\quad$ System of models in the evacuation planning process.

\section{Validation}

Tools resulting from the project are applied to verify the Local Civil Protection Plan (LCPP) of Melito Porto Salvo in the province of Reggio Calabria in Italy. By adopting the project guidelines, the plan is tested for a specific event that partly involves the municipal area. The scenario simulated concerns an incident involving a tank transporting dangerous goods which on a workday morning $(8.00 \mathrm{am}-12.00)$ is leaking. As a result the mayor decides that the surrounding area must be evacuated.

\subsection{Characteristics of the study area}

The municipal area covers about $35,300,000 \mathrm{~m}^{2}$. In this area there are 10,483 residents and 2,432 workers (Table 2). After the event, based on information about the type and quantity of hazardous goods, the mayor identifies an area of 
about 43,000 $\mathrm{m}^{2}$. In this area, on an average working day morning, 255 residents and 225 employers are present. They therefore have to reach the refuge area indicated (Table 2).

\subsection{Emergency planning process}

The emergency planning process of the Municipality complies with Italian Law 225/92. In the Provincial Civil Protection Plan (PPPC) of Reggio Calabria, Melito Porto Salvo is listed as a Mixed Operative Centre. Hence the Municipality draws up a Local Civil Protection Plan (LCPP). The main documents of the planning process assume dimensions represented in Table 3.

\subsection{Application in the internal emergency planning process}

After experimentation, the system of models resulting from project SICURO are specified, calibrated and validated. The main attributes and relative parameters are summarized in Table 4. These models are applied to verify the LCPP of Melito and to estimate evacuation times for the study area. The estimates of evacuation times are validated by comparing results of application models and results obtained from a real evacuation in the same area.

Table 2: $\quad$ Characteristics of study area.

\begin{tabular}{lll}
\hline & Municipality & Experimental area \\
\hline Area $\left[\mathrm{m}^{2}\right]$ & $35,300,000$ & 42,990 \\
Population & 10,483 & 255 \\
Employees & 2,432 & 225 \\
\hline
\end{tabular}

Table 3: Dimensions of local emergency planning process.

\begin{tabular}{llll}
\hline Planning dimension & Italian Law no. 225/92 & PPPC & LCPP \\
\hline Area & National & Local & Local \\
Temporal & Strategic & Tactical & Operative \\
Study in depth & Directional & Directional & Practicable \\
\hline
\end{tabular}

Table 4: $\quad$ Principal attributes and parameters of models.

\begin{tabular}{|c|c|}
\hline ATTRIBUTES & PARAMETERS \\
\hline 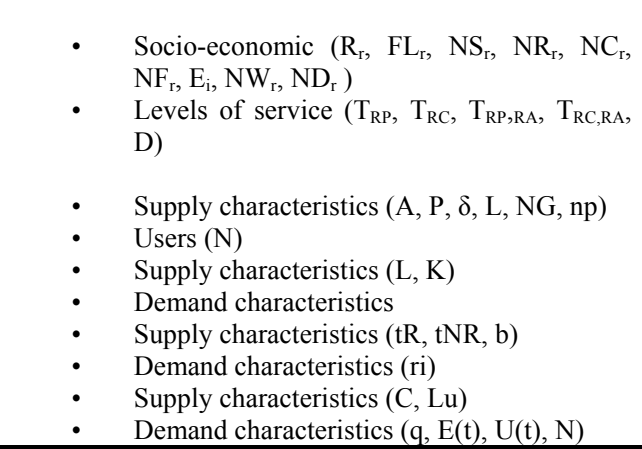 & $\begin{array}{ll}\text { - } & \alpha_{\mathrm{i}} \\
\text { - } & \mathrm{m}_{\mathrm{p}}(\mathrm{h}) \\
\text { - } & \mathrm{m}_{\mathrm{ER}}(\mathrm{h}) \\
& \lambda_{\mathrm{W}}(\mathrm{h}), \lambda_{\mathrm{C}}(\mathrm{h}), \lambda_{\mathrm{S}}(\mathrm{h}), \lambda_{\mathrm{ED}} \\
\text { - } & \xi_{\mathrm{k}} \\
\text { - } & \mathrm{a}, \mathrm{b}, \mathrm{c}, \mathrm{d}, \mathrm{e}, \mathrm{f} \\
\text { - } & \mathrm{s} \\
\text { - } & \beta_{\mathrm{i}} \\
\text { - } & \alpha_{\mathrm{i}} \\
\text { - } & \beta_{\mathrm{R}}, \beta_{\mathrm{NR}} \\
\text { - } & \alpha \\
& \alpha\end{array}$ \\
\hline
\end{tabular}




\section{References}

[1] G. E. Cantarella, E. Cepollina, G. Delfino, M. Di Gangi, A. Pratelli, C. Rindone, F. Russo, A. Vitetta, Linee guida per la redazione dei piani di evacuazione mediante la simulazione dei sistemi di trasporto in condizioni di emergenza (Laruffa editore, Reggio Calabria, 2005).

[2] M. de Luca, Manuale di pianificazione dei trasporti, CNR - Progetto Finalizzato Trasporti 2 (Franco Angeli Editore, Milan, 2000).

[3] M. Di Gangi, Velonà P., Safety of users in road evacuation: pedestrian outflow models in a building (in the same proceedings).

[4] Law no. 225of 24 February 1992, Istituzione del Servizio nazionale della protezione civile (Gazz. Uff., 17 March, no. 64, Suppl. ordinario, Italy, 1992).

[5] F. Russo, G. Chilà, Safety of users in road evacuation: demand model (in the same proceedings).

[6] F. Russo, C. Rindone, Obiettivi, vincoli e strategie generali per la pianificazione dei sistemi di trasporto (Proceedings of XXVII Conferenza Italiana di Scienze Regionali, Pisa, 2007).

[7] F. Russo, C. Rindone, Processo integrato di pianificazione e di progettazione delle infrastrutture di trasporto (Proceedings of XXVII Conferenza Italiana di Scienze Regionali, Pisa, 2007).

[8] F. Russo (edited by), Evacuazione dei sistemi urbani. Metodi quantitativi per l'analisi di un sistema di trasporto in condizioni di emergenza (Franco Angeli, Milano, 2004).

[9] F. Russo, A. Vitetta, Risk evaluation in a transportation system. (International Journal of Sustainable Development and Planning, Vol. 1, Issue 2, 2006).

[10] F. Russo, A. Vitetta, Safety of users in road evacuation: general methodology and main results (in the same proceedings).

[11] A. Vitetta, G. Musolino, A. Marcianò, Safety of users in road evacuation: supply and supply-demand interaction models for users (in the same proceedings).

[12] A. Vitetta, A. Polimeni, A. Quattrone, Safety of users in road evacuation: design of path choice models for emergency vehicles (in the same proceedings).

[13] A. Vitetta, V. Assumma, Safety of users in road evacuation: simulation of refuge's area for users (in the same proceedings). 